\title{
Low exercise among children with asthma: a culture of over protection? A qualitative study of experiences and beliefs
}

Brian Williams, Gaylor Hoskins, Jannette Pow, Ron Neville, Somnath Mukhopadhyay and Joanne Coyle

\begin{abstract}
Background

Research shows that children are insufficiently active in most affluent societies. Although children with asthma may particularly benefit from physical activity, they are
\end{abstract} less active than their peers.

Aim

To explore the reasons for low physical activity levels among children with asthma and to identify strategies to improve activity.

Design of study

A qualitative study using in-depth interviews and focus groups.

Setting

Six GP practices, a Paediatric Respiratory Unit, and four schools in Tayside, Scotland.

Method

Purposive sampling identified 30 children with asthma, their parents $(n=38)$ and school staff $(n=28)$, who were interviewed or took part in focus groups. Data were examined using constant comparative analysis.

\section{Results}

The lower level of activity among children with asthma was supported by a climate of fear among parents and teachers about what was safe and possible for the child. Restrictions were imposed because of perceived dangers of exercising in the presence of 'triggers'. Physical activity was regarded as a threat to be managed rather than something beneficial. Teachers found it difficult to distinguish between children who were physically incapable of exercise due to asthma and those who were unmotivated. GPs were unknowingly drawn into the controversy by children and parents who cite medical advice to sanction exemption from exercise.

\section{Conclusion}

GPs and asthma nurses need to provide clear management plans explaining what is appropriate and safe in terms of exercise on a child-by-child basis, to counter the considerable misunderstanding and disagreement among children, parents, and teachers. Keywords

asthma; children; exercise; primary health care; qualitative research.

\section{INTRODUCTION}

Asthma accounts for one in five of all child GP consultations in the UK. ${ }^{1}$ Its' prevalence is six times higher than in 1976, ${ }^{2,3}$ affecting one in five children between the ages of 2 and 15 years. ${ }^{4}$ The UK also has one of the highest prevalence rates of wheeze and asthma in 13-14 year olds. ${ }^{4}$ Consequently, it poses a significant burden and serious challenge to the health service.

Physical activity during childhood improves cardiovascular fitness, self-esteem, motor skills, and bone development. ${ }^{5}$ However, it has specific benefits for children with asthma, including reduced hospital admissions, reduced school absenteeism, fewer consultations with GPs, reduced medication, ${ }^{6}$ and improved ability to cope with asthma. ${ }^{7}$ Despite these

B Williams, BSc, PhD, director of the Social Dimensions of Health Institute and reader in behavioural science; J Coyle, $B S c, M S c, P h D$, research fellow, University of Dundee and St Andrews, Dundee. G Hoskins, BSc, MSc, PhD, research fellow, Tayside Centre for General Practice, University of Dundee, Dundee. J Pow, RGN, BSc, PhD, school nurse, Fife Primary Care Trust, Leven, Fife. R Neville, MD, FRCGP, MRCGP, DRCOG, GP partner, Westgate Medical Practice, Menzieshill, Dundee. S Mukhopadhyay, MBBS, PhD, DCH, MD, chair in paediatrics, Royal Alexandra Children's Hospital, Brighton.

Address for correspondence

Brian Williams, Social Dimensions of Health Institute (University of Dundee and University of St Andrews), Airlie Place, Dundee, DD1 4HJ, Scotland UK.

E-mail: b.y.williams@chs.dundee.ac.uk

Submitted: 9 November 2009; Editor's response: 28 January 2010; final acceptance: 18 May 2010.

\section{(0)British Journal of General Practice}

This is the full-length article of an abridged version published in print. Cite this article as: Br J Gen Pract 2010; DOI: 10.3399/bjgp10X515070 
benefits, rates of physical activity among young people with asthma are lower than their nonasthmatic peers, ${ }^{8-12}$ and are continuing to decline as rates fall more generally among young people in most industrialised nations. ${ }^{13,14}$

Three interconnected factors affect participation in physical activity by children with asthma: the illness beliefs of young people; ${ }^{15,16}$ parental and family beliefs; ${ }^{9,17}$ and the knowledge of teachers and organisational arrangements in schools. ${ }^{18-21}$ There is little research about the precise nature of these beliefs or the influence they have on activity levels. This study sought to explore the ways in which children's, parents', and school staff's beliefs about asthma and exercise influenced the child's willingness to engage in physical activity, in order to identify effective strategies to improve activity levels.

\section{METHOD}

Children were recruited through six GP practices and a paediatric respiratory unit in Tayside, Scotland. A purposive sample of children (aged 6-14 years) with moderate or severe asthma according to British Thoracic Society definitions were identified using a computer-assisted search of medical records. The sampling strategy reflected factors known to be associated with activity level: symptom severity, age, sex, and rural/urban living. ${ }^{22,23}$ Thus broadly equal numbers of children were selected from these categories.

When a patient was identified as appropriate for inclusion, their GP or consultant contacted the parents by letter, seeking permission for the researcher to approach them. The researcher sent information sheets and telephoned to answer questions and seek consent. Interviews with children only took place if the child understood what was being asked of them. Forty-one parents were contacted of whom nine declined. Thirty children (Table 1) and 38 parents were eventually interviewed. Two parents participated in eight interviews, while 22 interviews involved one parent (typically mothers). Involvement depended on the availability and choice of parents themselves.

Permission was obtained from the Tayside Educational Development Service to conduct four focus groups in two primary and two secondary schools. Ten physical education (PE) teachers, seven primary teachers, three guidance teachers (who instruct on personal development), two school nurses, two activity co-ordinators, two head teachers, and two deputy head teachers participated in the study. A number totalling from five to eight people participated in each group and the different occupations were fairly evenly represented in each.

\section{How this fits in}

Exercise improves general health status, and reduces GP consultations and medication use among children with asthma. The findings from the study show that lower levels of activity reported among children with asthma were strongly influenced by parental beliefs about the child's physical capability and fears about the safety of exercising in the presence of perceived 'triggers'. This resulted in limitations being imposed on the intensity and duration of physical activities.

\section{Data collection}

A female researcher with extensive experience of interviewing children and adults conducted the interviews. The interviewer used props such as drawings and games to build rapport with younger children. ${ }^{24,25}$ The topic guide was based on theory and the limited literature in the area; this provided broad prompts for exploring beliefs and knowledge about asthma, symptom perception, experience of treatment, and attitudes towards exercise (Box 1). The interviews lasted between 20 minutes and 1.5 hours. Each parent was interviewed immediately after the child using a modified topic guide (Box 2) and issues raised by the child where appropriate. Parent interviews lasted approximately 1.5 hours. All interviews took place in the family home and were digitally recorded.

Focus groups with school staff were conducted on school premises by the same researcher. These lasted for approximately 1 hour and explored staff's knowledge and experience of working with children with asthma.

\section{Analysis}

The constant comparative technique was used within a framework approach to analyse the transcripts. ${ }^{26}$ This meant, first, 10 transcripts were read and assigned initial categories and codes (familiarisation). Second, these were compared with other categories within and across transcripts, and with concepts in the literature. Third, the analysis was developed by cross linking categories and concepts to generate new meanings through the creation of charts which focused on the emerging themes (charting). Finally, these new concepts were linked to produce new interpretations (mapping and

Table 1. Age and sex of children.
\begin{tabular}{lccc} 
School status and age & Males & Females & Total \\
\hline Primary: 6-8 years & 3 & 5 & 8 \\
\hline Primary: 9-11 years & 6 & 4 & 10 \\
\hline Secondary: 12-14 years & 6 & 6 & 12 \\
\hline Total & 15 & 15 & 30 \\
\hline
\end{tabular}




\section{Box 1. Topic guide: children.}

\section{Topics}

1. Everyday life interests

Initial questions exploring child's interests and hobbies

2. Knowledge of asthma

3. Experience of symptoms and perceptions of symptoms as problematic

4. Experience and perceptions of treatment

5. Attitudes towards exercise/ physical activity and barriers/problems
6. Perceptions of views of others

7. Perceived impact of asthma on physical activity

9. Return to interests and hobbies

\section{Questions}

Younger children

- Can you draw a picture of the thing you like to do most of all?

- Tell me about your drawing.

- Who is in it?

-What are you/they doing?

- You like to do ... because ... ?

-What do you want to be when you grow up?

Older children

- What do you like to do after school? What's your favourite thing you like to do?

- What about the weekends?

- What do you like doing with friends?

- What do you want to do when you leave school?

- What do you want to be when you're older?

- I've heard that lots of people have asthma but I don't really know what it is. Can you tell me?

- Can you draw a picture (younger children) and tell me what it is?

- How do you get it?

- When did you find out you had asthma?

- How did you find out? What did you think about it?

- What's it like having asthma? What happens when you've got it?

- Does it bother you? How?

- Is there anything you can't do because you've got asthma?

- Have you ever had to stop doing anything?

- How do you feel about that?

- Are there any differences between what your friend can do and what you can do?

- Is there anything that makes you breathless, starts you off wheezing? (explore triggers etcetera)

- What do you have to take for your asthma?

- How do you take them?

- When? Can you show me?

- Can it (they) help? And they help (don't help) because ... ?

- (Bring in what they said they liked doing.)

- So you said you liked to ... is that exercise?

- What is exercise? What things are exercise?

- What's your favourite? It's your favourite because ... ?

- What do you like about exercise/being active? How do you feel after exercise?

-What's your least favourite exercise? Because ... ?

- How do you feel after this exercise?

- Do people have to do exercise?

- People have to do exercise because ... ?

- Are you supposed to exercise when you've got asthma?

- You're supposed/not supposed to because ...?

- What are the things you like about being active?

- What would your 'ideal' activity be? Is there anything you would like to try?

- Do you think your parents/teachers/friends think you're good at exercise/sport?

- How do you feel about that?

- Do you have to do anything before exercise/physical activity for your asthma?

- How do you feel after exercise/running around?

- Is there anything that starts you off wheezing or coughing? What do you do?

- What makes it worse?

- What helps your asthma?

- What's the best thing about school holidays?

- What's the most exciting thing you've ever done?

- What's the most exciting thing you'd like to do? interpretation). The process was assisted by NVivo software for qualitative analysis. ${ }^{27}$

Data collection and initial analysis occurred simultaneously, allowing the researchers to formulate conceptual ideas and test them through further questioning and probing. Interviewing 


\section{Box 2. Topic guide: parents.}

\section{Topics}

1. Knowledge of asthma

2. Meaning and impact of diagnosis

3. Perceptions of symptoms as problematic

4. Perception of treatment

5. Knowledge and attitudes towards physical activity and asthma

6. Barriers/problems in engaging in exercise/physical activity

7. Perceived impact of asthma on physical activity

\section{Questions}

- What is asthma?

- What do you think causes it?

- When did you find out your child (name) had asthma?

- Can you tell me a little about how you found out it was asthma? How did you feel about it?

- How has it affected your child (name)? Are you concerned about any problems your child might face in the future?

- How would you say it has affected you? The family in general?

- Can you tell me a little about the treatment? What does it involve?

- Who would you say is responsible for seeing that the treatment is done? Has that always been the case?

- Do you think the treatment helps (name)? Why is that?

- Is there anything that bothers/concerns you about the treatment/medication? Why?

- Is your child supposed to exercise when they have asthma? Why? Why not? Are there any forms of exercise or physical activity they can't do? Why?

- What types of exercise or physical activity does your child do? Where do they do it? With whom? When do they exercise?

- What kinds of exercise do other family members do? When? Where? With whom?

- What would you say your child's favourite form of physical activity is? What things do they like doing? Why?

- What do you think their least favourite is?

- What don't they like doing? Why?

- What do other family members enjoy doing? Why?

- What do you enjoy doing? Why?

- Are there any forms of physical activity and exercise you don't like doing? Why?

- How do you feel after exercise (favourite/least favourite)?

- What would your 'ideal' activity be? Why?

- Are there any types of physical activity that your child would like to try? Why? Is this possible? If no, why not?

- Do you think asthma affects your child in any way when they exercise? If it does: How?

- How do you feel about it?

- If not: Could you tell me a little about what they do to control/cope with symptoms?

Is there anything that causes an asthma attack? What makes it worse?

- What do you have to do when you have asthma?

- What helps your asthma?

- What do you think might encourage children with asthma to take more exercise? stopped when theory saturation was reached; that is, until the additional data did not add to the developing theory.

Several strategies were employed to improve the accuracy and validity of the data. Regular meetings were held to check the interpretation of key texts, codes and categories. Deviant cases were identified to ensure transcripts were not analysed selectively. Two coders checked 10 transcripts for intercoder verification.

\section{RESULTS}

The study found that although medical advice was frequently cited by parents and young people to explain reduced participation in activity, it was in fact their beliefs about 'capability', 'safety', and 'motivation' that most strongly influenced the child's willingness to take part in physical activity and their parents' willingness to support it.

\section{Citing medical opinion to sanction exemption from school sports}

According to school staff, advice from GPs was frequently cited by parents and children when seeking exclusion from school sports. Teachers felt disempowered and unable to contradict medical opinion even if they thought it was unfounded:

\section{'I don't know what kind of advice that these kids} get when they go to the doctor ... but it certainly doesn't seem to come across to us that the advice from the doctor is "You still need to be doing physical activity ... It seems to be more that "My doctor said l've got asthma and I can't do it".' Jim (PE teacher, secondary school C)

However, in apparent contradiction, many parents commented that GPs had encouraged their children to exercise and had stressed that asthma should not 


\section{Box 3. Perceived triggers of asthma. \\ Beliefs about the causes of asthma symptoms \\ 'External' triggers 1) Environmental \\ - Weather \\ - Hot-cold \\ - Damp-dry \\ - Air quality \\ - Pollution/fumes \\ - Allergens (for example, pollen) \\ 2) Behavioural \\ - Overexertion \\ - Intensity of exercise \\ - Duration of exercise \\ - Smoking \\ 'Internal' triggers $\quad 3$ ) Psychosocial \\ - Nerves/nervousness \\ - Stress/life events \\ - Getting upset \\ 4) Biological \\ - Genetic \\ - Infection/cold/virus \\ - Underdevelopment of body \\ prevent the child from engaging in physical activities:}

'... I was told that although you have asthma it doesn't stop you doing things ... The GP and asthma nurse emphasised it ... cause Helen [the nurse] said to us "Get him right down that Ferry [seafront] and get walking right along".' Parent 11 (mother of boy aged 14 years).

Some parents $(n=8)$ however, reported they had not received any advice from practice staff and did not know about the health benefits of exercise:

Interviewer (I): 'Is Susan supposed to exercise when she has asthma?'

Parent: 'I have no idea. Just as a family we do try and encourage it you know ... but I really don't know. They've never said "Look swimming or whatever would help" ... If it did help we would take her regularly'. Parent 6 (mother of girl aged 14 years)

Contrary to the views of school staff, none of the parents stated that medical opinion discouraged exercise. Rather, what appeared to influence parents' support of physical activity, and the child's willingness to take part in it, was their beliefs about the child's physical 'capability' and the 'safety' of exercising in the presence of perceived 'triggers'.

\section{Capability: asthma as a physical barrier}

The reluctance to engage in certain activities arose from a belief that asthma placed an actual physical limit on the intensity and duration of activity that was possible for the child:

'[My son is] all right if he just cycles out with his friends or goes to the local farm ... But his dad'll take him out on an 8 mile cycle ... it's just too much'. Parent 17 (mother of boy aged 9 years)

The extent to which the child exerted themselves depended on their (and their parents') interpretation of physiological signals such as breathlessness. For some, the onset of any breathlessness was a sign that the child had reached the limits of their capability. Parents and children feared that going beyond those limits would provoke more severe asthma symptoms:

I: 'So if you've got asthma are you supposed to exercise as well?'

Jessica: 'Yeah. You are supposed to exercise even if you have asthma ... But not too much running if you have asthma'.

I: 'So how come you're not to run about too much?'

Jessica: 'Well it's 'cause of my asthma. It's because I cough and l've got to use my inhaler. That's why'. Girl 12 (aged 9 years).

Others placed even more absolute limits on themselves, that is, the child would not participate in the activity at all because of the fear of the onset of symptoms:

'And having races. You sort of want to do it but you don't. 'Cause you know it would sort of not really help, but your friends all do it and they like have a laugh'. Girl 20 (Kirsty, aged 13 years)

\section{Safety: activity as a danger}

Even where a parent or child believed that he/she was potentially 'capable' of being physically active, parents and children were concerned about safety, seeing exercise as a threat to be managed rather than as something beneficial. Primary school age children appeared less concerned about safety, whereas older children, and particularly girls, voiced concern. Concerns about safety stemmed from beliefs about the degree to which particular activities exposed them to perceived triggers of asthma (Box 3). These came from personal experience and information they received from their GP. The triggers included environmental factors, such as the weather (hot or cold, dry or damp), air quality (pollution/fumes), 
allergen (for example, pollen); and behavioural factors, such as overexertion, stress, anxiety, and others smoking. Overexertion was the most commonly reported trigger of asthma symptoms, especially breathlessness:

'My bus that I get to come home only comes at $3.30 \mathrm{pm}$ and my school gets out at $3.25 \mathrm{pm}$ so I have to run practically so by the time I get to the bus I am panting you know. I have to take my inhaler'. Girl 6 (Susan, aged 14 years)

Children believed they could 'overexert' themselves by doing the activity too intensively (running too fast) or for too long (duration). For some, it was better not to do the activity for as long or as fast as other children. Girls were more likely to report preventing asthma symptoms by scaling down activity. Many parents and children believed their GPs supported a certain type of physical activity that was less intensive and did not expose the child to triggers. However, a minority of children $(n=7)$ did attempt to exercise for longer durations and/or more intensively by using inhalers and rest periods to relieve their breathlessness:

I: 'Are you supposed to exercise when you've got asthma?'

Jack: 'Yes. You can still exercise. You just have to limit yourself. When you get chesty you just have to stop and take your inhaler and let it cool down and then keep going. When I'm walking Lurchers [my dog]. I just like have to take my inhaler - it's 7 miles'. Boy 11 (aged 10 years)

The general tendency to ascribe much breathlessness to asthma rather than seeing it as a normal response to exertion suggested that some symptom misinterpretation was common and could lead to misplaced perceptions of risk.

\section{Motivation: the value of physical activity}

PE teachers believed that many young people with asthma could engage in activities, but frequently lacked motivation and used their asthma as an 'excuse'. They commented that some parents seemed over cautious and teachers felt they could not enforce participation where parents had objected:

'... it's easier for the mum or the dad to write a note than it is to challenge them ... because if they're not active themselves they don't understand how important it is that the kids are active ... so I think it's changing the perceptions at home is a big part of it'. Andrew (PE teacher, secondary school D)
Teachers believed that this was part of a wider problem where unmotivated children would cite a range of medical conditions to be exempt from activities. Girls were seen as less likely to participate than boys and more likely to use asthma as a reason. However, this appeared more common at secondary school with few primary school teachers reporting that children used asthma to support exemption.

Children were motivated to take part in physical activity because of its personal and social, rather than health, benefits. They participated in games or sports because they were 'fun'; promoted a sense of community, belonging, and acceptance within a social group; and by performing well it enhanced their self-esteem:

I: 'Is it better when your friends go with you [to dancing classes]?'

Laura: 'Yeah cause sometimes you get to join dances together and make them into a dance, and you get to show everyone. You get to see who is the best at it. So that's how it's good when your friends are there'. Girl 8 (aged 9 years)

However, these social benefits, in particular social acceptance, could be undermined if the perceived triggers limited their ability to participate fully. This left the child unmotivated and prompted a further reduction in participation. For boys there was a strong negative sanction against non-participation especially in team activities such as football:

Christopher: 'I really like playing football but when I'm running with the ball I get awful breathless, I stop with the ball and I end up getting the ball taken off of us ...'

I: 'How do you feel about that?'

Christopher: 'Everybody in the playground they go like that if I tell them it is my asthma they go "Oh you're rubbish".' Boy 7 (aged 10 years)

But teachers appeared less concerned about whether the child valued the activity than whether the activity was safe for the child. Teachers wanted to be able to assess a child's capability and set the child activities appropriate to their health. However, in practice only a minority felt confident in doing this.

\section{DISCUSSION}

\section{Summary of main findings}

The findings show that the lower level of physical activity among children with asthma is supported by a climate of confusion and even fear among parents and teachers about what is safe and possible. Doubts about the child's capability and fears about safety in the presence of triggers caused parents to 
limit physical activities for their children. The key problem for parents, children, and teachers was recognising if asthma symptoms arose during exercise and appropriately responding to them. One misperception identified in this study was the possible over-attribution of breathlessness to asthma, when it may have been the normal consequence of exertion or have resulted from a lack of physical fitness.

Although most parents believed that medical opinion encouraged exercise, they also felt that exercise (especially overexertion) was a major trigger of an asthma attack. This apparent contradiction meant that some parents would veto physical activities for their child in school, and scale down their exercise at home. Moreover, GPs were unwittingly drawn into this controversy when parents and some unmotivated children cited medical opinion to sanction non-participation at school. Medical sanctions together with lack of knowledge about asthma, undermined efforts of school staff to engage pupils in physical activity. However, quantitative data on the scale, distribution, and reasons for specific school activity exemption by young people is currently unavailable.

\section{Strengths and limitations of the study}

The study was comprehensive for a qualitative study involving 30 children, 38 parents, and 28 school staff. All interviews and focus groups were carried out by a researcher with extensive experience of interviewing children and adults. Data were collected in an iterative fashion, generating rich detailed descriptions. This allowed the research team to identify similarities and differences in the beliefs and experiences of participants.

However, the study was conducted in a single region of Scotland and the results may not be applicable to other regions with different demographics. Therefore, a larger survey study encompassing different geographical areas would be useful in establishing the frequency and distribution of the issues identified.

\section{Comparison with existing literature}

Although children with asthma may especially benefit from physical activity, they are less active than their peers. ${ }^{8,9}$ Research has confirmed the link between parents' perceptions of risk and physical activity levels in their children. ${ }^{9}$ A US study of 137 parents found that children whose parents believed that the child would become ill from exercise were more likely to be inactive. ${ }^{9}$ Children of parents with elevated risk perceptions also have higher GP consultation rates. ${ }^{2}$ But research shows that parental knowledge is often poor and misperceptions common ${ }^{17,28}$ and, therefore, many of the fears identified in the study may be misplaced. Although activity can trigger asthma symptoms, research shows that people with asthma can exercise safely if appropriately medicated. ${ }^{29-31}$

Experimental research shows that young people with asthma frequently misinterpret breathlessness as asthma, when it is actually due to low aerobic fitness stemming from avoiding exercise. ${ }^{6}$ For the vast majority of children, exercise tolerance has been shown to be limited by muscular factors and not the lungs. ${ }^{32}$ Even at exercise exhaustion, pulmonary reserve is considerable..$^{30}$ Moreover, where physical activity does lead to genuine asthma symptoms this should not automatically mean abstaining from exercise as it may simply reflect the inefficient preventative use of inhalers. ${ }^{33}$ This could readily be addressed through programmes designed to enable young people to extend carefully the intensity and duration of their exercising. ${ }^{33}$

Yet in UK schools, studies have shown a deficiency of knowledge about asthma ${ }^{18,34-36}$ and this has led to a lack of confidence among staff in engaging such children in exercise. Such restrictions have also been identified in US studies. ${ }^{17,37,38}$

\section{Implications for clinical practice and future research}

Primary care professionals could have a pivotal role in promoting and supporting exercise among children with asthma if they address the fears of children and parents about 'capability' and 'safety'. Primary care professionals could give children and parents action plans to take to school which provide information on preparing for physical activity and managing any symptoms related to the activity. This would also include guidance for teachers on how to support the child. Engagement in activity outside the school will continue to rest on the value that the child and parents attach to physical activity. Lang et al recently found that the strongest predictors of participation were parents' beliefs that activity could improve a child's asthma. ${ }^{9}$ However, current evidence only supports the benefits of activity in terms of cardiovascular and aerobic function, but not in terms of reducing asthma symptoms. ${ }^{32,39}$ Nevertheless, practitioners could still utilise these physiological benefits to encourage parents and children to extend carefully the duration and intensity of physical activities for children.

Further research could establish more precisely: the frequency and distribution of beliefs about 'capability', 'safety', and 'motivation'; children's and parents' accuracy in interpreting and identifying asthma symptoms; and the scale and distribution of physical activity exemption at schools. 


\section{Funding}

Chief Scientist Office, Scottish Government CSO reference number: $\mathrm{CZH} / 4 / 152$.

\section{Ethical approval}

Ethical approval was gained from the Tayside Research Ethics committee (04/S1401/37).

\section{Competing interests}

All authors declare that there were no competing interests.

\section{Acknowledgements}

We would like to thank the children, parents, and schoo staff for taking part in this study, and practice, hospital, and school staff for making it possible.

\section{Discuss this article}

Contribute and read comments about this article on the Discussion Forum: http://www.rcgp.org.uk/bjgp-discuss

\section{REFERENCES}

1. National Asthma Campaign. An audit of children's asthma in the UK. Asthma J 2002; 8(2): 3-11.

2. National Asthma Campaign. Out in the open. A true picture of asthma in the United Kingdom today. Asthma J 2001; 6(3): 3-14.

3. Smyth RL. Asthma: a major pediatric health issue. Respir Res 2002; 3(Suppl 1): S3-S7.

4. ISAAC. Worldwide variations in the prevalence of asthma symptoms: the International Study of Asthma and Allergies in Childhood (ISAAC). Eur Respir J 1998; 12(2): 315-335.

5. White J, Flohr JA, Winter SS, et al. Potential benefits of physical activity for children with acute lymphoblastic leukaemia. Pediatr Rehabil 2005; 8(1): 53-58.

6. Welsh L, Kemp JG, Roberts RG. Effects of physical conditioning on children and adolescents with asthma. Sports Med 2005; 35(2): 127-141.

7. Van Veldhoven NH, Vermeer A, Bogaard JM, et al. Children with asthma and physical exercise: effects of an exercise programme. Clin Rehabil 2001; 15(4): 360-370.

8. Glazebrook C, McPherson AC, Macdonald IA, et al. Asthma as a barrier to children's physical activity: implications for body mas index and mental health. Pediatrics 2006; 118(6): 2443-2449.

9. Lang DM, Butz AM, Duggan AK, Serwint JR. Physical activity in urban school-aged children with asthma. Pediatrics 2004; 113(4): 341-346.

10. Meyer A, Machnick MA, Behnke W, Braumann KM. Participation of asthmaic children in gymnastic lessons at school. Pneumologie 2002; 56(8): 486-492.

11. Sawyer SM, Fardy HJ. Bridging the gap between doctors' and patients' expectations of asthma management. J Asthma 2003; 40(2): 131-138.

12. Yeatts K, Shy C, Sotir M, et al. Health consequences for children with undiagnosed asthma-like symptoms. Arch Pediatr Adolesc Med 2003; 157(6): 540-544.

13. Andersen LB, Harro M, Sardinha LB, et al. Physical activity and clustered cardiovascular risk in children: a cross-sectional study (The European Youth Heart Study). Lancet 2006; 368(9532): 299-304.

14. Dollman J, Norton K, Norton L. Evidence for secular trends in children's physical activity behaviour. Br J Sports Med 2005; 39(12): 892-897; discussion 897.

15. Callery P, Milnes L, Verduyn C, Couriel J. Qualitative study of young people's and parents' beliefs about childhood asthma. $\mathrm{Br} J$ Gen Pract 2003; 53(488): 185-190.
16. Velsor-Friedrich B, Vlasses F, Moberley J, Coover L. Talking with teens about asthma management. J Sch Nurs 2004; 20(3): 140-148.

17. Mansour ME, Lanphear BP, DeWitt TG. Barriers to asthma care in urban children: parent perspectives. Pediatrics 2000; 106(3): 512-519.

18. McCann D, McWhirter J, Coleman H, et al. The prevalence and management of asthma in primary-aged schoolchildren in the south of England. Health Educ Res 2002; 17(2): 181-194.

19. Clark NM, Partridge MR. Strengthening asthma education to enhance disease control. Chest 2002 121(5): 1661-1669.

20. Fillmore EJ, Jones N, Blankson JM. Achieving treatment goals for schoolchildren with asthma. Arch Dis Child 1997; 77(5): 420-422.

21. Heap E, Kalra D, Moore A, et al. Emergency asthma inhalers in school. Arch Dis Child 2004; 89(6): 590.

22. Physical Activity Task Force. Lets make Scotland more active: $a$ strategy for physical activity. Edinburgh: Scottish Government Department of Health, 2003.

23. Department of Health. On the state of the public health: the Annual Report of the Chief Medical Officer of the Department of Health for the year 1996. London: Department of Health, 1997.

24. Sartain SA, Clarke CL, Heyman R. Hearing the voices of children with chronic illness. J Adv Nur 2000; 32(4): 913-921.

25. Morison M, Moir J, Kwansa T. Interviewing children for the purposes of research in primary care. Prim Health Care Res Dev 2000; 1: 113-130.

26. Patton M. Qualitative research and evaluation methods. Thousand Oaks, CA: Sage, 2001.

27. Richards L. Using NVivo in qualitative research. Bundoora: QSR, 1999.

28. Lai KY, Lam KKL, Lam SC, et al. Exploring parents' understandings and concerns on self-management of childhood asthma. Hong Kong Pract 2005; 27(May): 172-178.

29. Lucas SR, Platts-Mills TA. Physical activity and exercise in asthma: relevance to etiology and treatment. J Allergy Clin Immunol 2005; 115(5): 928-934.

30. Orenstein DM. Pulmonary problems and management concerns in youth sports. Pediatr Clin North Am 2002; 49(4): 709-721, v-vi.

31. Sheth KK. Activity-induced asthma. Pediatr Clin North Am 2003, 50(3): 697-716.

32. Ram FS, Robinson SM, Black PN. Effects of physical training in asthma: a systematic review. Br J Sports Med 2000; 34(3): 162-167.

33. Coleman H, McCann DC, McWhirter J, et al. Asthma, wheeze and cough in 7- to 9-year-old British schoolchildren. Ambulatory Child Health 2001; 7: 313-321.

34. Hussey J, Cahill A, Henry D, et al. National school teachers' knowledge of asthma and its management. Ir J Med Sc 1999; 168(3): 174-179.

35. Brookes J, Jones K. Schoolteachers' perceptions and knowledge of asthma in primary schoolchildren. Br J Gen Pract 1992; 42(365): 504-507.

36. Bevis M, Taylor B. What do school teachers know about asthma? Arch Dis Child 1990; 65(6): 622-625.

37. Firrincieli V, Keller A, Ehrensberger R, et al. Decreased physical activity among head start children with a history of wheezing: use of an accelerometer to measure activity. Pediatr Pulmonol 2005; 40(1): 57-63.

38. Schmitz KH, Lytle LA, Phillips GA, et al. Psychosocial correlates of physical activity and sedentary leisure habits in young adolescents: the Teens Eating for Energy and Nutrition at School study. Prev Med 2002; 34(2): 266-278.

39. Carlsen, KH, Carlsen KCL, Exercise-induces asthma. Paediatr Respir Rev 2002; 3(2): 154-60. 